\title{
CRM as a tool to maintain the competitiveness of enterprises in the global digital economy
}

\author{
Josef Botlík ${ }^{1, *}$, and Milena Janáková ${ }^{1}$ \\ ${ }^{1}$ Silesian University in Opava, School of Business Administration in Karvina, Department of \\ Informatics and Mathematics, Univerzitní náměstí 1934/3, 73340 Karviná, Czechia
}

\begin{abstract}
.
Research background: Globalization is characterized by the interconnection of national economies, which may be more vulnerable in this way. Economic and social shocks caused by the global nature of the socio-economic environment have now shown, especially in connection with covid19, the need for a deeper focus of companies on customers.

Purpose of the article: The need for communication, the search for new market opportunities, and the resumption of production in the post-crisis period could be significantly affected by the use of digital technologies aimed at clients and customers. The ongoing research "Application of systems for customer relationship management in the environment of small and medium-sized enterprises" has shown that customer orientation can be significantly supported and streamlined by using Customer relationship management (CRM) systems. The paper compares the use of CRM in EU countries and identifies critical points.

Methods: Using methods of system analysis, especially mathematical prediction, statistical methods, and multicriteria analysis, the use of CRM in EU countries is compared in relation to selected factors of the digital economy.

Findings \& Value added: Years with major declines and disproportions have been identified. The declines in developed economies (Germany, France, Austria etc.) in 2019 are specific, related mainly to the use of new forms of customer service. It turns out that although companies are streamlining their marketing efforts through CRM and focusing on maximizing potential through customers, CRM is only an integral part of ICT and can be replaced in the global environment by other tools of the digital economy.
\end{abstract}

Keywords: CRM; digital economics; EU; crisis; globalization

JEL Classification: $D 22 ; F 01 ; F 60$

\footnotetext{
${ }^{*}$ Corresponding author: botlik@,opf.slu.cz
} 


\section{Introduction}

The impact of the crisis situations currently facing the globalized world in the context of a coronavirus pandemic can be mitigated by using appropriate tools. The priority is to retain potential customers. In the initial phase, therefore, a research question was asked whether the impact of Covid 19 on the development of companies can be reduced by a suitable form of communication between companies and potential and existing customers. The fact that companies were looking for new ways to reach customers and potential clients during the pandemic seemed to support this research question. The fact that the Covid19 pandemic has caused a significant increase in problems is pointed out by many studies and authors, such as $[1,2]$ mentioning the main principles of the context of payment risks on the part of consumers, vouchers in connection with advance payments etc., and related enforcement problems, a wide range of instruments is defined, such as a voucher system [2]. The authors' experience is based on similar crisis stages, especially the global financial crisis in 20072009 and its course in Taiwan. Although the authors do not confirm the positive impact of this form of economic support as a stimulus tool based on analysis of income elasticity of consumption, they confirm the nature of their analysis of CRM as one of the stimulus tools. In the pandemic context, however, a new fact is mentioned at the same time, the implementation of virtual relationships as determinants of possible savings in an efficient and flexible supply chain, ie in CRM [3]. The authors have shown that in a flexible supply chain, virtual work can be a way to maintain and build long-term relationships with suppliers and customers. In this context, it was hypothesized that the use of CRM applications as a management tool for CRM can effectively normalize post-pandemic developments. Achieving close relationships with customers is a progressive tool for gaining competitive advantages, the post demonstrates the importance of implementing customer relationships in the EU, where CRM can contribute to improving competitiveness in the long run. The fact that companies can maintain their efficiency if they have satisfied and loyal customers is pointed out by many studies and authors, for example in a study [4] the authors confirm that CRM provides companies with significant benefits, especially in gaining competitiveness. The authors mention general facts here, namely the fact that in order to achieve the set goals, companies must first identify and analyze their customers and conclude that in this regard, not only changing market conditions but also effective communication are important to increase satisfaction and loyalty ties to customers. In this study ([4]), the authors identify of the dominant corporate segment (large companies) and different forms of customer reactions to the forms of CRM used, the research can predict the need to look at CRM comprehensively and deal with other tools (Enterprise Resource Planning), the ERP system typically covers four main areas in which customer relationships are identifiable, ie finance (sometimes referred to as economics), human resources, production and logistics (for non-manufacturing companies only logistics or operation or design) and marketing and sales (sometimes just marketing) [5]. A similar nature of customer relations is mentioned by the authors [6]. They show that CRM tools cannot be taken out of the context of IoT (Internet of Things) in the current digitalized world, a characteristic concept of Industry 4, resp. IoE (Internet of Everything), analyze IoT and big data (BD) and their impact on CRM investments. Using the Analytical Hierarchy (AHP) process methodology, the authors tried to prioritize the factors influencing investments through IoT and BD in modern CRM. Furthermore, based on the research, the authors predict the importance of identifying connections between companies and customers, especially in the segment of large companies, thus confirming the conclusions of the previously mentioned studies. The e-CRM industry is also developing rapidly [7]. However, studies show in this segmenta low level of customer satisfaction. The authors point out the need to identify means to increase the overall level of customer satisfaction and only then begin to consider the transition from customer satisfaction to broader loyalty strategic 
marketing goals. The complexity of the issue is also pointed out by other authors, the study [8] focuses on corporate social responsibility (CSR) and the importance of messaging in CSR communication, a trend that calls for a change in business orientation from short-term to long-term goals and from maximum to optimal profit. From this point of view, the authors again mention the need for comprehensive data, including not only economic data, but also information from the environmental and social field. The authors demonstrate that a systematic approach to the management of socially responsible activities, risk identification and opportunities, including CRM, can contribute to increasing the competitiveness of business and maintaining the possibility of long-term business. In the context of heuristics, we can mention a study [9], in which the authors draw attention to CRM technologies. According to their research, the priority in adopting CRM technologies was corporate culture, followed by social relations and creativity. If we mention technologies, some authors [10] state that the role of social media technologies (SMT) in strengthening CRM capabilities has not yet been explored in the adoption of new technologies. The initial hypothesis cannot be verified at present, but it is possible to predict the development of the use of CRM systems and deduce on the basis of experience $([1,2])$ possible trends in the impact of the pandemic on the corporate environment.

\section{Methods}

In the this phase of the research, data concerning the use of CRM applications in individual EU countries were analyzed. The data series were taken and modification from Eurostat databases, the data series 2009-2019 was used, the analysis took place at the level of EU countries. The data "Enterprises using software solutions, like CRM to analyze information about clients for marketing purposes [tin00116]" was chosen as the default data series, the values were defined as $\%$ of enterprises with at least 10 people employed in the given NACE (Nomenclature of Economic Activities is the European statistical classification of economic activities) sectors. The analysis took place in several stages. In the first stage, the identification of minimum, maximum and average values was performed and the basic trend of the development of the respective region (increase, decrease) was indicated. Based on the average values, the missing data (highlighted in Figure 1) were added for Greece and Turkey (2012) and for Iceland and Serbia (2015) so that the Exponential Adjustment method could be applied (the remaining missing values were interpolated by this method). For Liechtenstein, Switzerland, Montenegro, Albania, Bosnia and Herzegovina, it was not possible to consolidate the data series in the given time interval. In the second stage, development trends for 2020 and 2021 were predicted. The method of exponential smoothing and its implementation in MS Excel 2019 was chosen as the method. The exponential smoothing method determines values at time point $t$ based on all available past values. The weighted least squares method is used to estimate the parameters, where the weights decrease exponentially towards the past, where the effect of observation on the value at point $t$ gradually weakens, the meaning (weight) of the data point for the prediction value decreases exponentially with time from prediction. The balanced Yt values of the time series are determined to minimize the value of expression (1).

$$
\begin{gathered}
\sum_{j=1}^{\infty}\left(Y_{t-j}-\hat{Y}_{t-j}\right)^{2} \alpha^{j} \\
0<\alpha<1
\end{gathered}
$$

The value of $\alpha$ (2) indicates the degree of intensity of the influence of past observations. We will assume that the time series does not contain seasonal and cyclical components and therefore has a shape according to the required interpolation function (3). The trend 
component of a given time series is substituted according to the type of exponential smoothing. Substitution is performed either by a constant (the trend can be considered constant in short sections of the series), by a linear function or by a quadratic polynomial (4).

$$
\begin{gathered}
Y_{t}=T_{t}+\varepsilon_{t} \\
T t=\beta_{0}+\beta_{1} t+\beta_{2} t_{2}
\end{gathered}
$$

Where $T_{t}$ is the trend component of a given time series, $\beta_{i}$ are the parameters whose value is estimated (more closely [11]). The calculations were performed using the FORECAST.ETS function of the MS Excel program. The algorithm used for the calculation is referred to as the "AAA version of the Exponential Smoothing (ETS) algorithm", the triple exponential smoothing is used (4). The function is entered in the form (5)

FORECAST.ETS(target_date, values, timeline, [seasonality], [data_completion], [aggregation])

Where "target_date" is a mandatory argument specifying the data point at which we predict the value. "Values" is a mandatory argument specifying an array of historical values for which we predict additional points. "Timeline" is a mandatory field indicating an independent field or range of consistent numeric data with a defined interval step. "Seasonality" is an optional argument, automatic seasonality detection was used in the selected analysis. The "data_completion" argument was chosen so that the missing data was interpolated from adjacent points. "Aggregation" indicates how to aggregate values with the same timestamp. The AVERAGE value was chosen for analysis. In the next phase of the research, correlation analysis was used. Correlation coefficients were used to identify additional clusters. Correlation analysis was performed using the "Data Analysis" tool in the MSExcel program again.

Correlation coefficients for data series of individual monitored countries were gradually determined. The used correlation coefficient equation (6) for measuring the dependence uses Pearson's correlation coefficient $r$, which measures the linear dependence of two random variables with a two-dimensional normal distribution.

$$
\operatorname{Correl}(X, Y)=\frac{\sum(\mathrm{x}-\bar{x})(\mathrm{y}-\bar{y})}{\sqrt{\sum(\mathrm{x}-\bar{x})^{2}} \sum(y-\bar{y})^{2}}
$$

Where $\bar{y}$ and $\bar{x}$ are the sample means AVERAGE(array1) and AVERAGE(array2)., The time series of individual states are gradually inserted as an array.Due to the nature of the data, no significance test was performed, coefficients were used to create clusters based on positive and negative correlations. The breakdown of intervals for clusters was as follows:

$$
<-1,-0,6),<-0,6,-0,2),<-0,2,0,2),<0,2,0,6),<0.6,1>.
$$




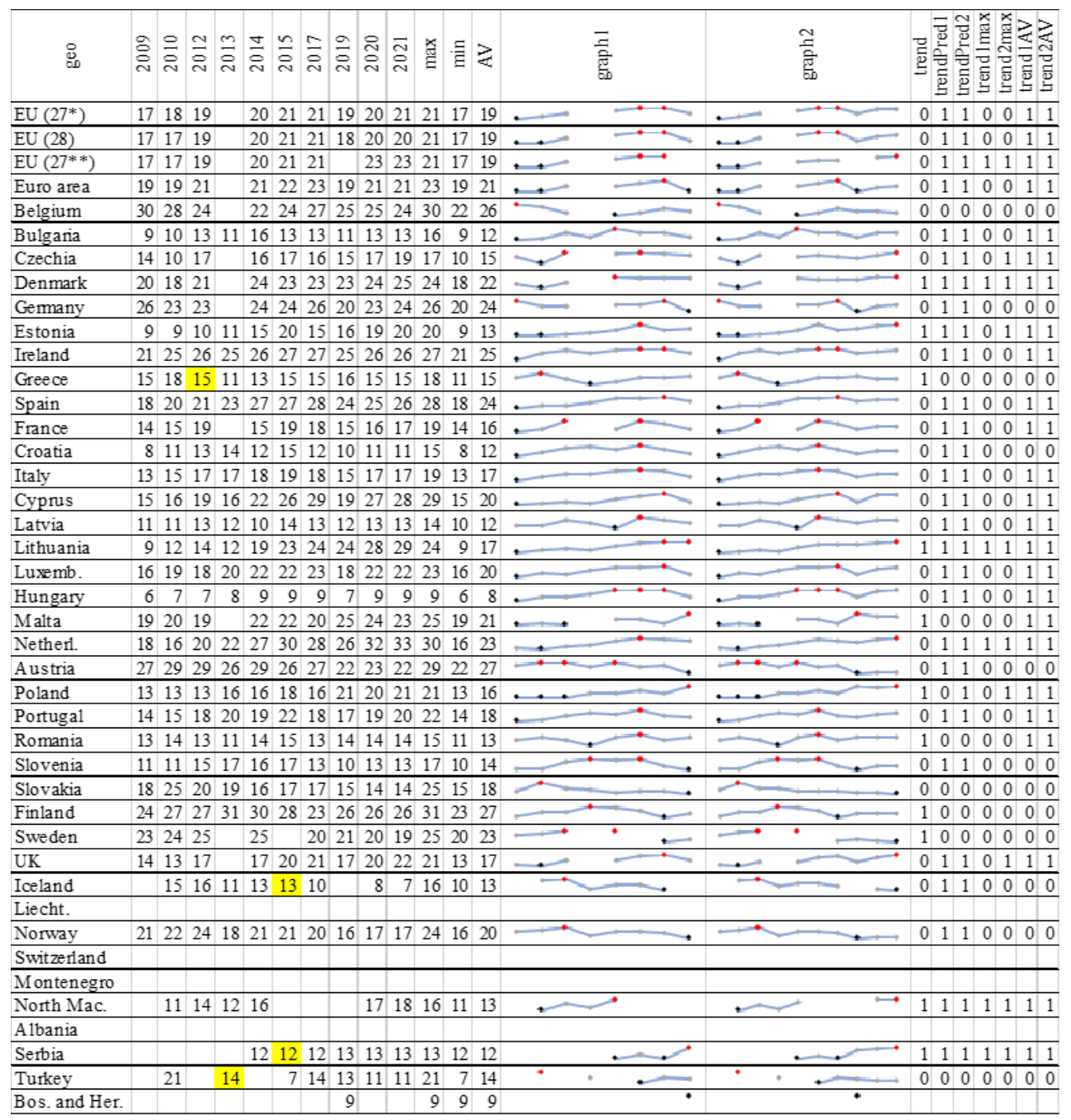

Fig. 1. Trends in the use of CRM.

\section{Results and Discussions}

Based on the calculated values of trend, trendPred1, trendPred2, trend1max, trend 2 max, trend1 AV and trend2AV (8) (in Figure 2 as $t_{1}$ to $t_{7}$ ), was cluster analysis performed.

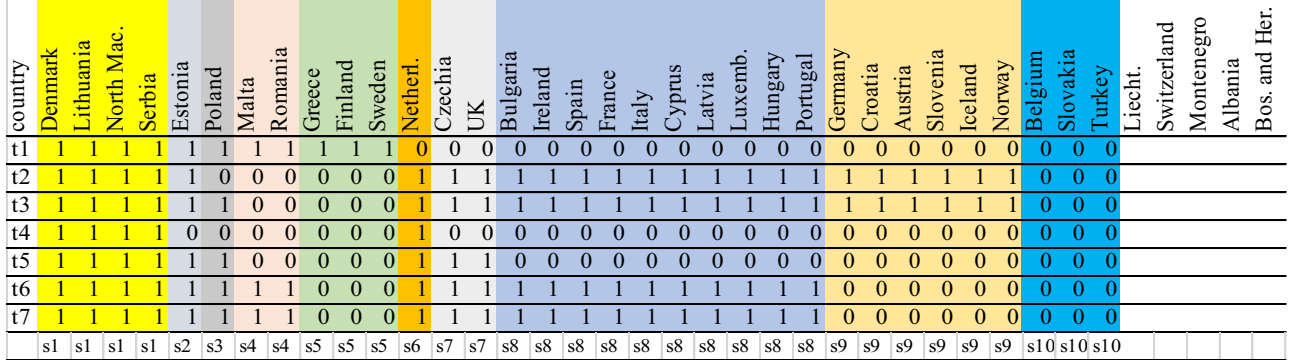

Fig. 2. Clusters - CRM trend. 
The clusters were formed according to (9), where the weight of individual values of $t_{i}$ was taken into account. These clusters, based on the predicted values for 2020 and 2021, were compared with clusters created based on correlation analysis.

$$
\begin{aligned}
& \text { IF (value (2019)>value (previous year)) THEN (value (trend)) }=1 \text {; ELSE (value(trend) }=0 \\
& \text { IF (value }(2019)<\text { value }(p r 2020)) \text { THEN (value }(\text { trendPred1) })=1 \text {; ELSE }(\text { value }(\text { trendPred1) })=0 \\
& \text { IF }(\text { value }(2019)<\text { value }(\text { pr2021) THEN }(\text { value }(\text { trendPred2 }))=1 \text {; ELSE }(\text { value }(\text { trendPred2 }))=0 \\
& \text { IF }(\text { value }(2020)>\text { value }(\max (2009: 2019) \text { THEN }(\text { value }(\text { trend } 1 \text { max }))=1 \text {; ELSE }(\text { value }(\text { trend } 1 \text { max }))=0 \\
& \text { IF }(\text { value }(2021)>\text { value }(\max (2009: 2019) \text { THEN }(\text { value }(\operatorname{trend} 2 \max ))=1 ; \operatorname{ELSE}(\text { value }(\operatorname{trend} 2 \max ))=0 \\
& \text { IF (value }(2020)>\text { value }(\max (2009: 2019) \text { THEN }(\text { value }(\text { trend } 1 \mathrm{AV}))=1 \text {; ELSE }(\text { value }(\text { trend1 AV }))=0 \\
& \text { IF (value }(2021)>\text { value }(\max (2009: 2019) \text { THEN }(\text { value }(\text { trend2AV }))=1 \text {; ELSE }(\text { value }(\text { trend2AV }))=0
\end{aligned}
$$

Where pr2020 is the prediction of 2020, pr2021 is the prediction of 2021.

In the first phase, it was a surprising finding that the use of CRM in EU countries decreased in most countries (17 countries) between 2017 and 2019, as shown in Figure 1. The figure shows the time series "Enterprises using software solutions, like CRM to analyze information about clients for marketing purposes", the values are given by $\%$ of enterprises. EU $(27 *), E U(28), E U(27 * *)$ and Euro area values indicate EU (27 countries - from 2020), EU (28 countries), EU (27 countries - 2007-2013) and Euro area data (changing composition). Graph1 in the figure shows the minimum and maximum values for each country. The value of minimum, maximum and average is calculated in all numerical series. The values in columns 2020 and 2021 are predicted trends. Column graph2 shows the development, maxima and minima of the time series with predicted values, columns trend, trendPred 1 , trendPred 2 , trend 1 max, trend $2 \max$, trend $1 \mathrm{AV}$ and trend $2 \mathrm{AV}$ are the ratios according to formulas (10). The prediction indicates a change in the development trend to a growing one, in 9 countries (Czechia, Denmark, Estonia, Lithuania, Netherland, Poland, UK, North Macedonia and Serbia) the year 2021 is identified as the maximum. From the values in column graph1 it is clear that in general the EU country is characterized by a decrease in the use of CRM. Although it is predicted to be influenced by values throughout the euro area, it is not expected to create a maximum. If we create clusters of countries based on predicted and actual values, we influence the predicted trend in 2019 compared to 2017 (value of "trend" in Figure 1, value of t1 in Figure 2), see (8), we get 3 dominant clusters (s1, s8, s9).

$$
s_{k=1}^{k=\max }=\mathrm{f}\left(\forall t_{1}^{t 1=0} \min _{t 1=1}^{t=t_{i=2}^{i=n}} \sum_{j=2}^{n} t_{j}\right)
$$

Clusters are formed using a function that, based on the value of $\mathrm{t} 1$, clusters countries according to the minimum of other $t_{i}$. for all available $t_{i}(9)$.

The largest cluster (s8): Bulgaria, Ireland, Spain, France, Italy, Cyprus, Latvia, Luxembourg, Hungary and Portugal. This group (10 countries) is characterized by a decrease in the number of CRMs in the observed interval, predicted values are the same in both years (2020 and 2021) higher than in 2019. At the same time, these values are higher than the average value, but do not reach the values of the maximum data series 2009-2019. The second largest group (s9, 6 countries) consists of Germany, Croatia, Austria, Slovenia, Iceland and Norway is again characterized by a decrease in CRM, higher predicted values compared to 2019, the values of predicted data are lower than the average of the data series. The third largest cluster (s1) consists of 4 countries, Denmark, Lithuania, Northern Macedonia and Serbia and they are not always involved (in case Denmark stagnates) at the end of the observed interval, but there are still high values in both predicted areas that are higher than the averages and maxima. If we compare the measured values of the formed clusters with the values of the euro area, it is evident that despite the common characteristics, the individual data series show disproportions, as can be seen in figure 3, where the first cluster (right part of the picture) shows then an obvious discrepancy in Serbia (left part). 

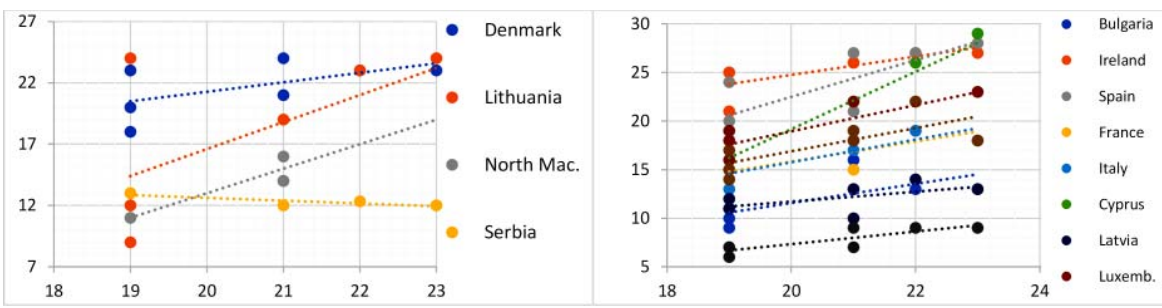

Fig. 3. Disproportion in clusters.

Due to the stated disproportions, a correlation between individual data series was found according to (6). Based on the values of positive and negative correlation, clusters were again formed, The figure 4 shows the clusters according to the positive correlation (according to the negative correlation, the clusters came out the same).

\begin{tabular}{|c|c|c|c|c|c|c|c|c|c|c|c|c|c|c|c|c|c|c|c|c|c|c|c|c|c|c|c|c|c|c|c|c|c|c|c|c|}
\hline & 志 & & & & & & & & 总 & 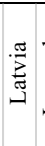 & 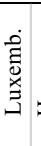 & $\begin{array}{l}\text { 窎 } \\
\text { of } \\
\text { 恶 }\end{array}$ & 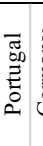 & 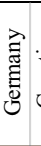 & ل & 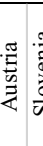 & & 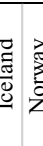 & 5 & 苟 & & 导 & 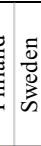 & 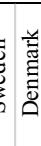 & 墨 & 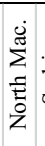 & : & ల. & & 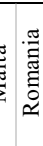 & $\frac{\vec{E}}{\vec{\Xi}}$ & 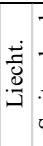 & 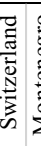 & & & \\
\hline & 6 & & 6 & 0 & 0 & 0 & 0 & 0 & 0 & 0 & 0 & 0 & 0 & 5 & 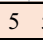 & 5 & & 5 & & & & 7 & 7 & $7 \quad 12$ & 212 & 1 & 12 & 3 & & 0 & 6 & 0 & 0 & 0 & & \\
\hline$y$ & 3 & 3 & 3 & 4 & 4 & 4 & 4 & 4 & 4 & 4 & 4 & 4 & 4 & 2 & 2 & 2 & 2 & 2 & 2 & 9 & 1 & 11 & 1 & 112 & 212 & 12 & 12 & 3 & 3 & 5 & 3 & 0 & 0 & 0 & & \\
\hline$\Rightarrow$ & 0 & 0 & 0 & 6 & 6 & 6 & 6 & 6 & 6 & 6 & 6 & 6 & 6 & 4 & 4 & 4 & 4 & 42 & 41 & 121 & 11 & 1111 & 111 & 10 & 0 & 0 & 0 & 8 & 8 & 99 & 14 & 0 & 0 & 0 & & \\
\hline D & 12 & 12 & 12 & 13 & 13 & 13 & 313 & 313 & 13 & 13 & 13 & 13 & 13 & 13 & 131 & 131 & 131 & 131 & 3 & 1 & 8 & 8 & 8 & 3 & 3 & 3 & 3 & 15 & $\begin{array}{lll}15 & 1\end{array}$ & 1717 & 78 & 0 & 0 & 0 & & \\
\hline & 11 & 11 & 11 & 9 & 9 & 9 & 9 & 9 & 9 & 9 & 9 & 9 & 9 & 8 & 8 & 8 & 8 & 8 & & 7 & & 5 & & 5 & 5 & 5 & & 3 & & 1 & 1 & 0 & 0 & 0 & & \\
\hline
\end{tabular}

Fig. 4. Clusters according to the positive correlation.

Clusters were again formed according to (9) with the difference that it was summarized all values, $t_{i}$ were formed by intervals (7), the frequencies of correlating countries were

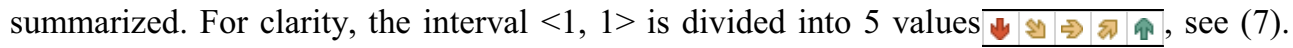
Despite the different methodology of clustering, where the waveforms of the entire data series were compared, not the deviations from the maximum, average and final values of the data series, similar 3 dominant clusters were identified as in the previous case.

CRM is undoubtedly a modern strategy that creates and maintains long-term and profitable customer relationships. CRM is used to plan and maintain processes aimed at strengthening competitiveness by creating corporate interactions with customers. This system collects and consolidates information from various sources in the company and, where possible, collects information from around the company to offer a unique real-time picture of each individual client, as mentioned, for example, [12]. CRM as a tool is not "selfsaving, its application and implementation must take into account the current state of knowledge and reflect the situation in the current social-economic environment. A study [13] based on behavioral economics presents a set of proposals for the strategic use of CRM. Specifically, the authors design a CRM application to increase competitiveness by making the customer relationship available based on heuristic decisions, creating customer interactions based on reference relationships based on profit access, the emphasis is on a heuristic approach rather than identifying customer relationships. The study shows that in the process of a crisis period, customers can temporarily tolerate lower quality because they usually do not engage in cognitive thinking. Furthermore, the authors state that quality does not have to reduce the space for companies to interact with customers and depends on the subjective view of customers. Although the analysis does not currently show a tendency to increase the use of CRM, the resulting prediction suggests a slight increase. As mentioned earlier, these tools are now being integrated into the environment of other information platforms, starting with ERP, cloud platforms IoT, IoE and e-commerce products. For example [14], they state that an e-marketing strategy is currently needed for corporate 
information flows. The relationship between the company and customers must be created by monitoring real customer preferences, and it is currently becoming a priority to identify customer requirements. Due to the fact that the scale of current information channels changes very quickly, it is not easy to achieve the monitoring of real customer priorities in standard ways. The development of CRM is moving to the level of systems based on personalized IT systems developed on the basis of specific requirements using cyberspace, the Internet and social networks. It is therefore necessary to focus further analyzes on monitoring the potential of online applicable channels, enabling direct involvement of customers in the CRM process. Although the findings of some studies [14] predicted an increase in CRM investment in 2018, which was not confirmed by practice, access to customers is still a fundamental marketing trend for modern companies. In order to compare the correctness of these opinions, other statistical data were compared within the Euro area, but due to the insufficient number of data was comparation made only for comparison of results, no relevant statistical evaluation was performed. The data are shown in Figure 5. The areas "E-commerce, customer relation management (CRM) and secure transactions", "Cloud computing services" and "Enterprises using ERP software", Percentage of enterprises, Euro area are compared. The figure 5 puting services: hosting of the enterprise's database, accounting software applications, CRM software“, e-CRMS: Enterprises using software solutions CRM“, e-CRMA: „Enterprises using CRM to analyse information about clients for marketing purposes", e-CRMC: „Enterprises using CRM to capture, store and make available clients information to other business functions“, ERP: „Enterprises who have ERP software package to share information between different functional areas". The size of the companies is indicated a: „All enterprises, without financial sector (10 persons employed or more)“, s: „Small enterprises (10-49 persons employed), without financial sector“, m: „Medium enterprises (50-249 persons employed), without financial sector", I:"Large enterprises (250 persons employed or more), without financial sector“. In the segment "Very small enterprises (0-9 persons employed), without financial sector" no relevant data was identified.

\begin{tabular}{|c|c|c|c|c|c|c|c|c|c|c|c|c|}
\hline & & 2010 & 2011 & 2012 & 2013 & 2014 & 2015 & 2016 & 2017 & 2018 & 2019 & graph \\
\hline $\mathrm{CC}$ & $\mathrm{a}$ & & & & & 11 & & 13 & & 16 & & 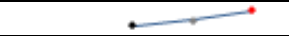 \\
\hline $\mathrm{CC}$ & $\mathrm{s}$ & & & & & 11 & & 11 & & 14 & & $\longrightarrow$ \\
\hline $\mathrm{CC}$ & $\mathrm{m}$ & & & & & 14 & & 17 & & 24 & & $\longrightarrow$ \\
\hline $\mathrm{CC}$ & 1 & & & & & 22 & & 30 & & 39 & & $\longrightarrow$ \\
\hline e-CRMS & $\mathrm{a}$ & & & & & 34 & 36 & & 37 & & 36 & 2 \\
\hline e-CRMS & $\mathrm{s}$ & 26 & & & & 30 & 33 & & 34 & & 32 & 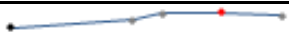 \\
\hline e-CRMS & $\mathrm{m}$ & 44 & & & & 49 & 53 & & 52 & & 51 & $\longrightarrow$ \\
\hline e-CRMS & 1 & 57 & & & & 62 & 65 & & 65 & & 63 & $\longrightarrow$ \\
\hline e-CRMA & $\mathrm{a}$ & 19 & & 21 & & 21 & 22 & & 23 & & 19 & $\longrightarrow \rightarrow$ \\
\hline e-CRMA & $\mathrm{s}$ & 16 & & 18 & & 19 & 20 & & 20 & & 16 & $\longrightarrow$ \\
\hline e-CRMA & $\mathrm{m}$ & 30 & & 33 & & 33 & 35 & & 35 & & 31 & $\longrightarrow$ \\
\hline e-CRMA & 1 & 43 & & 44 & & 45 & 47 & & 47 & & 43 & $\longrightarrow$ \\
\hline $\mathrm{e}-\mathrm{CRMC}$ & $\mathrm{a}$ & 27 & & 30 & & 32 & 35 & & 36 & & 34 & $\longrightarrow$ \\
\hline e-CRMC & $\mathrm{s}$ & 24 & & 27 & & 29 & 31 & & 32 & & 31 & $\longrightarrow$ \\
\hline $\mathrm{e}-\mathrm{CRMC}$ & $\mathrm{m}$ & 42 & & 46 & & 48 & 51 & & 51 & & 50 & $\longrightarrow$ \\
\hline $\mathrm{e}-\mathrm{CRMC}$ & 1 & 55 & & 57 & & 60 & 63 & & 64 & & 62 & $\longrightarrow$ \\
\hline ERP & $\mathrm{a}$ & 25 & & 26 & 31 & 36 & 43 & & 39 & & 38 & $\longrightarrow$ \\
\hline ERP & $\mathrm{s}$ & 19 & & 20 & 25 & 31 & 37 & & 34 & & 32 & $\longrightarrow$ \\
\hline ERP & $\mathrm{m}$ & 49 & & 51 & 58 & 62 & 69 & & 65 & & 63 & $\longrightarrow$ \\
\hline ERP & 1 & 72 & & 73 & 78 & 80 & 85 & & 82 & & 81 & $\longrightarrow$ \\
\hline
\end{tabular}

Fig. 5. Other applications - compare with CRM in Europe area.

Proposing future strategies for targeting and improving CRM with existing and potential consumers through a social media platform is also mentioned by other authors, eg. [15] or [16]. Other authors [17] see trends in CRM systems at the level of implementation of a 
controlled type of knowledge that can be used for further development of an intelligent system for managing customer satisfaction in the context of customer experience. If we summarize the findings of presented studies, they can be compared to the conclusions of the study [18], where the authors propose a holistic model. The discussion also shows trends in the transformation of standard CRM systems into a "Co-creating services with the customer" system [19], where CRM is replaced by the sharing of knowledge, skills and resources between the company and its customers. Similar trends are mentioned by other authors [20]. In the discussion, it is appropriate to mention the findings published [21] or [22], where the authors state that building and maintaining a good relationship with customers is essential for the long-term survival of the company, but should be preceded by Business Process Reengineering (BPR). At the end of the discussion, it is necessary to mention a study [23], which could clarify the declining tendencies in the deployment of CRM from a different perspective. It identifies potential risks of CRM deployment, especially the fact that technology provides companies not only with the opportunity to communicate better with customers, but also theft of customers or employees, illegal monetization (selling information to third parties), etc. These phenomena are described by authors as the dark side of CRM. The authors cite factors such as injustice, mistrust, opportunism and lack of transparency as barriers to customer support for CRM. Other authors also mention customer trust as one of the priority factors [24].

\section{Conclusion}

The aim of the post was to identify the use of CRM in EU countries, to identify clusters of countries with a similar approach to CRM and thus predict potential critical regions where the non-use of sophisticated tools can be a risk factor. A relatively interesting finding is the fact that CRM is not the prerogative of developed economies and that countries such as Germany, Iceland and Croatia are in one cluster. This fact testifies to the fact that CRM can not be seen only as a standardized tool, but in the context of other relationships. As the discussion showed, CRM cannot be seen as a closed, isolated system. Connection with other platforms, especially ERP, cloud services or social networks, may give the impression that CRM systems are less used by companies over time. Further comparison at the level of the Euro area shows that the percentage of the use of other systems (ERP) and e-commerce CRM system tools also has a declining trend in the period 2009-2019. Figure 5 shows that it is very likely that the trend is to move corporate applications to the cloud. Large enterprises are dominant in all monitored factors. Based on the calculation of the prediction of CRM development in the EU countries, the downward trend in using CRM sytems was not confirmed. Eleven countries were identified in which the percentage of companies using CRM increased (Denmark, Lithuania, North Mac., Serbia, Estonia, Poland, Malta, Romania, Greece, Finland, Sweden) in the period 2017-2019. In 2020, however, an increase compared to 2019 is already predicted for 24 countries and in 2021 even for 25 countries. It is also assumed that in 5 countries the share of companies will be higher in 2020 than the maximum for the period 2009-2019, in 2021 there may be 9 of these countries. A relatively interesting finding is the fact that CRM is not the prerogative of developed economies and that countries such as Germany, Iceland and Croatia are in one cluster. This fact supports the hypothesis that CRM can not be seen only as a standardized tool, but in the context of other relationships.

This paper was supported by the project no. SGS/19/2019, Application of Customer Relationship Management Systems in Small and Medium-sized Enterprises accepted in 2019. 


\section{References}

1. Alderman, R., et al. (2020). Consumer Law and Policy Relating to Change of Circumstances Due to the COVID-19 Pandemic. Journal of consumer policy, 43(3), 437450.

2. Lin, F., Chen, W. (2020). Did the Consumption Voucher Scheme Stimulate the Economy? Evidence from Smooth Time-Varying Cointegration Analysis. Sustainability 12(12), 4895.

3. Wyrwich-Plotka, S., Witkowski, J. (2016). Virtualization of work in global supply chains. Logforum, 12(4), 301-312.

4. Aktepe, A., Ersoz, S., Toklu, B. (2015). Customer satisfaction and loyalty analysis with classification algorithms and Structural Equation Modeling. Computers \& industrial engineering, 86, 95-106.

5. Monk, E., Wagner, B. (2011). Concepts in Enterprise Resource Planning, 4th edition. London: CENGAGE Learning Custom Publishing.

6. Abu Ghazaleh, M., Zabadi, A. M. (2020). Promoting a revamped CRM through Internet of Things and Big Data: an AHP-based evaluation. International journal of organizational analysis, 28(1), 66-91.

7. Taylor, S., Hunter, G. (2002). The impact of loyalty with e-CRM software and eservices. International journal of service industry management, 13(5), 452-474.

8. Moravcikova, K., Stefanikova, L., Rypakova, M. (2015). CSR reporting as an important tool of CSR communication. In C. Bektas (Ed.), 4th World Conference On Business, Economics And Management (pp. 332-338). Amsterdam: Elsevier science BV.

9. Hasani, B. Z. Z. (2016). Influential factors on reception of technology of customer relationship management (CRM) by employees. International journal of advanced and applied sciences, 3(1), 71-75.

10. Foltean, F. S., Trif, S. M., Tuleu, D. L. (2018). Customer relationship management capabilities and social media technology use: Consequences on firm performance. Journal of business research, 104, 563-575.

11. Brown, R. G., Meyer, R. F. (1961). The fundamental theory of exponential smoothing. Operations Research, 9, 673-685.

12. Jocovic, M., Melovic, B., Vatin, N., Murgul, V. (2014). Modern business strategy Customer Relationship Management in the area of civil engineering. Advances in mechatronics and control engineering III, 678, 644-647.

13. Huang, M. H., Pei-Hsiang, T., Wang, J., Chun-Shun, L. (2005). A Behavioral Economics Approach to Customer Relationship Management. In Pacific asia conference on information systems 2005 (pp. 712-720). Taipei: Natl Taiwan Univ.

14. Negoita, O. D., Purcarea, A. A., Popescu, M. A. M. (2018). A model for improving the connection between e-marketing and customers. In C. Bratianu, A. Zbuchea \& A. Vitelar (Eds.), Strategica: challenging the status quo in management and economics (pp. 933942). Bucharest: Polytechnic University of Bucharest.

15. Zolkepli, I.A., Kamarulzaman, Y. (2011). Exploring the Role of Perceived Media Needs and Technology Characteristics in Determining Social Media Adoption: Conceptual Framework. In H. Fulford (Ed.), 6th European conference on innovation and entrepreneurship, (pp. 1048-1055). Kuala Lumpur: Universiti Malaya Univ Malaya, Grad Sch Business. 
16. Kiron, D., Palmer, D., Phillips, A. N., Kruschwitz, N. (2012). What Managers Really Think About Social Business. Mit sloan management review, 53(4), 51-60.

17. Villanueva, H. E., Faed, A., Truffa, M. A. (2017). Knowledge Model To Manage Customer Satisfaction Based on Claims. In O. Hussain, L, Jiang, X. Fei, X., C. W. Lan $\&$ K. M. Chao (Eds.), 14th international conference on e-business engineering (pp. 195200). New York: IEEE.

18. Vaziri, J., Beheshtinia, M. A. (2016). A holistic fuzzy approach to create competitive advantage via quality management in services industry. Management decision, 54(8), 2035-2062.

19. Ghatak, R. R. (2020). Barriers analysis for customer resource contribution in value cocreation for service industry using interpretive structural modeling. Journal of Modelling in Management, 15(3), 1137-1166.

20. Galetto, M., Franceschini, F., Maisano, D. A., Mastrogiacomo, L. (2018). Engineering characteristics prioritisation in QFD using ordinal scales: a robustness analysis. European journal of industrial engineering, 12(2), 151-174.

21. Chang, H. H. (2007). Critical factors and benefits in the implementation of customer relationship management. Total quality management \& business excellence, 18(5), 483508.

22. Lindgreen, A., Palmer, R., Vanhamme, J., Wouters, J. (2006). A relationshipmanagement assessment tool: Questioning, identifying, and prioritizing critical aspects of customer relationships. Industrial marketing management, 35(1), 57-71.

23. Nguyen, B., Jaber, F., Simkin, L, (2020). A systematic review of the dark side of CRM: the need for a new research agenda. Journal of strategic marketing, 1-19.

24. Dehghanpouri, H., Soltani, Z., Rostamzadeh, R. (2020). The impact of trust, privacy and quality of service on the success of E-CRM: the mediating role of customer satisfaction. Journal of business \& industrial marketing. 